\title{
WORK LOCUS OF CONTROL AND BURNOUT IN POLISH PHYSIOTHERAPISTS: THE MEDIATING EFFECT OF COPING STYLES
}

\author{
MACIEJ WILSKI ${ }^{1,2}$, BARTOSZ CHMIELEWSKI ${ }^{1}$, and MACIEJ TOMCZAK ${ }^{1,2}$ \\ ${ }^{1}$ State School of Higher Professional Education, Konin, Poland \\ Department of Physiotherapy and Health Knowledge \\ ${ }^{2}$ University School of Physical Education, Poznań, Poland \\ Department of Physical Education, Sport and Rehabilitation
}

\begin{abstract}
Objectives: The aim of this study was to explain the relationship between work locus of control and burnout in Polish physiotherapists through the mediation of coping styles. In particular, we hypothesized that external work locus of control may have a positive direct relationship with burnout symptoms via positive relationship with emotion-focused and avoidant coping styles, and a negative relationship with problem-focused style. Material and Methods: We tested the mediational hypothesis using structural equation modeling of self-report data from 155 Polish physiotherapists. Results: The relationship between external work locus of control and physiotherapists' burnout was shown to be mediated by a positive relationship with emotion-focused coping and an inverse relationship with problem-focused coping. The variables included in the model explained about $15 \%$ of the variance of emotional exhaustion, $14 \%$ of depersonalization, and $14 \%$ of personal accomplishment. Conclusions: Physiotherapists perceiving the situation as difficult to control, feel more burned out when they use more emotion-focused strategies, and less problem-focused strategies. This indicates the importance of including both, problem-focused coping training and increasing the perception of the situation controllability in preventing physiotherapists' burnout programs.
\end{abstract}

Key words:

Burnout, Work locus of control, Coping style, Physiotherapist, Job stress, Poland

\section{INTRODUCTION}

Burnout is a serious problem in professional social services. It is defined as a reaction to chronic stress, experienced by people helping others. Burnout includes emotional exhaustion, depersonalization and reduced personal accomplishment [1]. Emotional exhaustion refers to lack of energy and depletion of emotional, physical and interpersonal resources [2]. Many researchers view burnout as a process, and emotional exhaustion is often referred to as its major characteristic [3]. Exhaustion is critical for the development of burnout [4] and leads to negative, uncaring, cynical attitudes of employees and their detached feelings toward other people, referred to as depersonalization [5]. The 3rd component of burnout, personal accomplishment, is postulated to be independent of the other 2 dimensions [6]. Reduced personal accomplishment refers

Source of financial support: State School of Higher Professional Education funds.

Received: April 4, 2014. Accepted: February 9, 2015.

Corresponding author: M. Wilski, State School of Higher Professional Education, Department of Physiotherapy and Health Knowledge, ks. Jerzego Popiełuszki 4, 62-510 Konin, Poland (e-mail: mwilski@wp.pl). 
to diminished feelings of competence and achievement at work [7].

Medical professions are associated with a high risk of burnout. Many previous studies documented a high prevalence of burnout among physicians and nurses [8-11]. Surprisingly, empirical research on burnout among physiotherapists has received little attention. This is surprising, given the fact that physiotherapists often provide services to people with disabilities who have various emotional problems. Physiotherapists often spend more time with a patient than physicians or nurses. Since the risk of burnout is determined by the amount of time spent with a patient [12] and the intensity of a patients' emotional demands [13], one may expect a particularly high level of burnout among physiotherapists.

This assumption was confirmed by one of the few studies dealing with the problem in question, carried out by Li Calzi et al. [14]. They studied a group of medical personnel (physicians, nurses, therapists and technicians), including 124 physiotherapy workers, and found that the latter presented with higher levels of professional exhaustion than nursing staff and physicians. Other studies, conducted in Japan [15], United States [16] and Cyprus [17], also confirmed that burnout constitutes a significant problem among physiotherapists. The aim of our study was to examine the incidence of burnout among Polish physiotherapists.

Most of the previous studies dealing with the problem in question centered around the relationship between burnout and its situational or individual correlates separately rather than on their interactions [18]. While some authors focused on the role of individual characteristics in burnout development, others explored the impact of work environment. According to Maslach et al. [19], in order to predict the level of burnout, one should consider interactions between individuals, their personality resources and work-related correlates. Apart from working conditions, one's susceptibility to burnout can be modified by various personality characteristics [20]. According to literature, work locus of control is one of the most often cited predictors of burnout $[3,21,22]$.

\section{Work locus of control and burnout}

Locus of control refers to the extent to which people attribute control over events to themselves or to external environmental factors [23]. People with an internal orientation believe that they can control their own lives and perceive a strong link between their actions and consequences thereof. Individuals with external orientation believe that their lives are controlled by other forces, such as luck or other people, and perceive themselves in a passive role with regard to external environment. According to Rotter [24], general locus of control is a stable personality trait, but control orientations often are situationally determined. Based on this assumption, many researchers perceive locus of control as a multidimensional construct, postulating that people differ in their beliefs regarding different areas of their lives [25]. Work locus of control is one of these context-specific subdimensions.

Work locus of control represents the extent to which people attribute rewards, reinforcements or outcomes at work to their own behavior [26]. High level of control at work (internality) is related to many positive outcomes, such as well-being [27], job satisfaction [25], job performance [28] and lower levels of work-related stress [29]. In turn, individuals who believe that work outcomes are controlled by luck or powerful others (externality), are more susceptible to stress [25], depression and emotional exhaustion [30], and have lower organizational commitment [26]. These variables are directly related to burnout.

Either the work locus of control or burnout depend on situational context [31]. Locus of control is inter alia determined by environmental factors [25,32]. Hard-working people characterized by internal orientation may form an external control of their outcomes at work if exposed to many obstacles, such as an authoritarian leader, inflexible 
system of work or high levels of stress. On the other hand, individuals with an external locus of control may change their perception of work and behavior at a workplace if working conditions promote their autonomy [31]. Therefore, work locus of control is perceived as a better predictor of work behavior and work-related criteria than the generalized measure of locus of control [25,33-35].

Work locus of control depends largely on the level of autonomy at the workplace. The level of physiotherapist's autonomy in decision making is country-specific, depending on the laws and policies that govern physiotherapy practice. Polish physiotherapists' autonomy in decision making is low due to the absence of a Physiotherapist Profession Act in the Polish law and superiority of physician's recommendations over a physiotherapist's diagnosis [36]. According to the Polish National Health Service, a patient may consult a physiotherapist only with a medical referral from a physician and with a diagnosis made by a physician (except for private visits where healthcare costs are nonrefundable). In practice, much of the physiotherapist's work often comes down to fulfilling the recommendations of a physician [36].

Moreover, a physiotherapist's sense of control is affected by a number of other factors, such as little promotion opportunities, a short career path, no visible effects of work resulting from the difficult and irreversible condition of the patients (e.g., spinal cord injury, multiple sclerosis, cerebral palsy), perceptions of not having a positive impact on the patient, a sense of incompetence, and lack of meaningful recognition for one's efforts and accomplishments [36-39]. In other words, the working conditions of physiotherapists in Poland, especially those working in the public sector, often favor the formation of an external locus of control.

Many studies have documented a strong relationship between perceived control and occupational burnout $[3,22,40,41]$. For example, poorer locus of control was shown to be associated with greater work-related stress, burnout [41], depression, emotional exhaustion and lack of accomplishments among nurses [30]. Furthermore, a negative correlation between internal control and emotional exhaustion was documented among mental health professionals [42] and firefighters [43]. A meta-analysis conducted by $\mathrm{Ng}$ et al. [44] revealed that internal locus of control is inversely related to overall burnout and its facets, such as emotional exhaustion, depersonalization and lack of personal accomplishments.

However, some authors demonstrated that the relationship between locus of control and burnout can be reversed in particular situations. Hipps and Malpin [45] found that in difficult work conditions, educators with external control orientation reported less job stress, emotional exhaustion and depersonalization than those with internal control orientations. Expanding the range of control of people who do not feel competent or have low levels of self-efficacy can lead to depersonalization [46] and negative health consequences [47]. According to Gan et al. [22], locus of control is not the determinant of burnout, but an accurate perception of controllability of the situation, an appropriate appraisal and matching of coping strategies. Consequently, in order to expound the relationship between work locus of control and burnout, one should include coping styles as an important mediating factor.

\section{Mediating effect of coping styles}

According to Lazarus and Folkman [48], coping is a set of behavioral and psychological strategies, defined as specific efforts employed to master, tolerate, reduce or minimize stress in certain situations. Endler and Parker [49] identified coping in a slightly different perspective, as a personality trait or a style that remains consistent in most situations. Actions that a person takes in particularly stressful situations result from an interaction between the characteristics of the situation and specific coping style of a given person [50]. This approach is based on an interactive 
model and emphasizes individual differences. Three main coping styles were proposed:

- problem-focused coping aims to alter the stressor via a direct action,

- emotion-focused coping involves self-preoccupation, fantasy or other conscious activities related to affect regulation,

- avoidance-oriented coping includes seeking out other people (social diversion) or engaging in a substitute task (distraction) [51].

Several studies analyzed the relationship between coping strategies and the level of burnout. For example, problem-focused strategies, such as active coping, are considered a factor reducing the level of burnout among nurses [52,53], case managers [54], mental health workers [4] and teachers [55]. However, most of the studies have shown that the use of an emotion-focused strategy is positively correlated with burnout, and it does not appear to be an adaptive coping style in the work environment. According to Wilkerson and Bellini [56], individuals who deal with problems by focusing on associated feelings, are more likely to develop burnout symptoms. A similar correlation was observed in the case of avoidance strategies. Withdrawal or avoidance coping were shown to be associated with mental health and levels of burnout [55,57-59]. However, some studies did not confirm such a simple correlation between coping strategies and burnout symptoms. Michielsen et al. [60] studied a large group of workers and showed that coping styles did not predict emotional exhaustion. In turn, Triplett et al. [61] analyzed a group of correctional officers and found that problem-focused strategies are ineffective in reducing overall stress and risk of burnout. Similar results were documented in a study of police officers, in whom emotion-focused coping, rather than problem-focused coping, was found to be associated with strain reduction [62]. In another study of 367 nurses, active coping was shown to result in emotional exhaustion [63], but this finding was attributed to poor opportunities of job control. Nurses who were high in active coping and had low control opportunities in their job were more frustrated than nurses who were low in active coping in the same situation. This evidence points to the importance of situational context in research on occupational burnout. In specific work situations, the use of a particular strategy can promote either an increase or a decrease in negative emotions and burnout.

Since both coping styles and locus of control were shown to be associated with burnout symptoms, the relationship between work locus of control and burnout was likely mediated by the use of coping styles or the level thereof. Effective coping was conceptualized as a key mediator of relationships between negative life events and psychological well-being [64]. Several studies documented links between different coping strategies and the perception of situation controllability $[22,65,66]$. For example, Elfstrom and Kreuter [66] found that the relationship between locus of control and emotional well-being of persons with traumatically-acquired spinal cord lesion was mediated by coping strategies. The results of most previous studies suggest that external individuals use fewer problemfocused strategies when dealing with stress $[65,67,68]$. Internal individuals with problem-focused skills feel that they can do something constructive in situations perceived as controllable, and as a result experience less negative emotions than persons using emotion-focused or avoidant styles [65].

Given the results of previous research, one may expect that the coping style may play a significant mediational role in the relationship between work locus of control and burnout. Namely, external work locus of control may impact the 3 dimensions of burnout through its negative influence on the problem-focused style, and positive influence on the emotion-focused and avoidance-oriented styles. Based on these theoretical speculations, we hypothesized that the relationship between work locus of control and burnout in physiotherapists was established with 
the aid of coping styles. Consequently, we proposed the following hypotheses:

- Hypothesis 1: There is a positive relationship between external work locus of control and emotion-focused style of coping with stress, and a positive relationship between emotion-focused style and burnout in physiotherapists.

- Hypothesis 2: There is a negative relationship between external work locus of control and problem-focused style of coping with stress, and negative relationship between problem-focused style and burnout in physiotherapists.

- Hypothesis 3: There is a positive relationship between external work locus of control and avoidance-oriented style of coping with stress, and a positive relationship between the avoidance-oriented style and burnout in physiotherapists.

\section{MATERIAL AND METHODS}

\section{Participants and procedure}

The study included 155 physiotherapists from 5 rehabilitation centers located in 5 different regions of Poland. The centers were selected due to wide variety of treated patients. The researchers were psychologists qualified to conduct research involving human subjects. The welfare and rights of human subjects were adequately protected, and informed consent was obtained from the study participants. The questionnaires were distributed to all participants, with an explanation of the aims of the research. The questionnaires were completed anonymously. Those who agreed to participate in the study were asked to read the questionnaire and answer the questions at the workplace. Participants were assured that the data would be treated as confidential. There were no missing data as the correctness of filling the questionnaire was checked immediately after receiving a set of forms. In the absence of data, respondents were asked to fill the gaps. The data was collected between March and June 2013.
Most of the participants were female (66\%) and married $(55 \%)$. The average age of our respondents was 37 years (standard deviation $(\mathrm{SD})=10.83$ ), and their average working experience amounted to 9.37 years $(\mathrm{SD}=5.66)$. Participants worked $43.65 \mathrm{~h}$ per week on average ( $\mathrm{SD}=10.27)$. The physiotherapists specialized in orthopedics (85\%), rheumatology (57\%), neurology $(25 \%)$, pediatric physical therapy $(21 \%)$ and sports rehabilitation (18\%). A smaller group specialized in cardiology (9\%), oncology (9\%) and pulmonology (2\%). The respondents could provide more than 1 answer to the question regarding their specialization.

\section{Measures}

Burnout

The level of burnout was assessed by Polish version of Maslach Burnout Inventory - Human Service Scale (MBI-HSS) [5,69]. This 22-item instrument has been widely used in surveys of burnout in medical professions. Maslach Burnout Inventory consists of 3 subscales: Emotional Exhaustion (measures the feelings of being emotionally overextended and exhausted by one's work), Depersonalization (measures an unfeeling and impersonal response toward recipients of one's service, care treatment or instruction), and Personal Accomplishment (measures feelings of competence and successful achievement in one's work).

Sample items are "I feel emotionally drained from my work" (Emotional Exhaustion); "I feel I treat some recipients as if they were impersonal objects" (Depersonalization); and "I have accomplished many worthwhile things in this job" (Personal Accomplishment). The items are rated on a 7-item frequency-based scale ( 0 - never, 6 - every day). High scores on Emotional Exhaustion and Depersonalization and low scores on Personal Accomplishment are indicative for burnout. Reliability and validity of this scale has been confirmed in numerous studies $[19,70]$. 


\section{Work locus of control}

Work locus of control was measured by Spector's [26] Work Locus of Control Scale (WLCS), which is a 16item instrument designed to assess the sense of control in the workplace. Each item consisted of 6 response choices, ranging from 1 ("disagree very much") to 6 ("agree very much"). The scale has equal numbers of internally and externally worded items. Sample items are "Getting the job you want is mostly a matter of luck" (external); and "People who perform their jobs well generally get rewarded" (internal). The internally-worded items need to be scored inversely. High scores correspond to externality, and low scores to internality. Work Locus of Control Scale represents a well-established, domainspecific measure of locus of control that has been widely utilized in rehabilitation-related research [71]. High reliability and validity of this scale has been repeatedly confirmed $[26,70]$.

\section{Coping style}

Forms of coping with stress were assessed by Endler and Parker's [49,50] Polish version of Coping Inventory for Stressful Situations (CISS) [72]. This 48-item questionnaire measures 3 coping styles: problem-oriented coping, emotion-oriented coping and avoidance-oriented coping. Respondents are asked to assess how much they engage in each coping activity when they encounter a difficult, stressful or upsetting situation. The scale requires examinees to choose among 5 Likert-type responses, ranging from "not at all" to "very much." Sample items are "Think about how I have solved similar problems" (problem-oriented coping); "Get angry" (emotion-oriented coping); and "Try to be with other people" (avoidance-oriented coping). The total score for each stress coping scale ranges from 16 to 80, with higher scores indicating a greater degree of coping activity. The CISS is widely used in research on coping styles in various occupational groups due to its high reliability and validity [73].

\section{Demographic variables}

In order to describe the research group, a demographic questionnaire was used to gather physiotherapists' personal data, such as sex, age, present marital status, work experience, weekly workload and specialization.

\section{Statistical analysis}

Mediation hypothesis was verified by mean of structural equation modeling, with work locus of control as an independent variable, stress coping styles as mediators and all 3 burnout scales as dependent variables. Indirect effects of the mediators were calculated. To assess the significance of the indirect effects, bias corrected bootstrapping was used [74-76]. To evaluate the fitting of models, Chi statistics, Comparative Fit of Index (CFI), and Root Mean Square Error of Approximation (RMSEA) were used. Insignificant value of $\mathrm{Chi}^{2}$ statistics, CFI $>0.9$ and RMSEA $<0.08$ indicated adequate model fitting. The values $>0.95$ and $<0.05$ pointed to a very good fit of the model [77].

\section{RESULTS}

First, relationships between the variables were identified (Table 1), and then 2 mediation models were proposed (Figure 1 and 2). Both models presented the style of coping with stress as a mediator of the relationship: work locus of control - burnout subscales.

The external work locus of control correlated positively with the emotion-focused coping style $(r=0.48$, $\mathrm{p}<0.001$ ), as well as with the avoidance-oriented coping style $(r=0.20, p<0.05)$, and showed an inverse correlation with the problem-focused style $(r=-0.25, p<0.01)$. In turn, emotion-focused coping style correlated positively with emotional exhaustion $(\mathrm{r}=0.32, \mathrm{p}<0.001)$ and depersonalization $(\mathrm{r}=0.34, \mathrm{p}<0.001)$, and was inversely correlated with personal accomplishments $(\mathrm{r}=-0.34, \mathrm{p}<0.001)$.

Moreover, problem-focused style was found to be inversely correlated with emotional exhaustion $(\mathrm{r}=-0.16$, 
Table 1. Correlations between work locus of control, stress coping styles and burnout in study group ( $\mathrm{N}=155)$

\begin{tabular}{lccccccc}
\hline \multirow{2}{*}{ Variable } & \multicolumn{7}{c}{ Pearson correlation coefficient } \\
\cline { 2 - 7 } & WLC & E & P & A & EX & DEP & PA \\
\cline { 2 - 7 } & 1.00 & $0.48^{* * *}$ & $-0.25^{* *}$ & $0.20^{*}$ & $0.36^{* * *}$ & $0.32^{* * *}$ & $-0.29^{* * *}$ \\
WLC & 1.00 & -0.08 & $0.30^{* * *}$ & $0.32^{* * *}$ & $0.34^{* * *}$ & $-0.34^{* * *}$ \\
E & & 1.00 & -0.08 & $-0.16^{*}$ & $-0.16^{*}$ & $0.20^{*}$ \\
P & & & 1.00 & 0.04 & 0.13 & 0.01 \\
A & & & & 1.00 & $0.44^{* * *}$ & $-0.43^{* * *}$ \\
EX & & & & & 1.00 & $-0.37^{* * *}$ \\
DEP & & & & & & 1.00 \\
PA & & & & & & &
\end{tabular}

WLC - work locus of control; E - emotion-focused coping style; P - problem-focused coping style; A - avoidance-oriented coping style; EX - emotional exhaustion; DEP - depersonalization; PA - personal accomplishment.

* $\mathrm{p}<0.05 ; * \mathrm{p}<0.01 ; * * \mathrm{p}<0.001$.

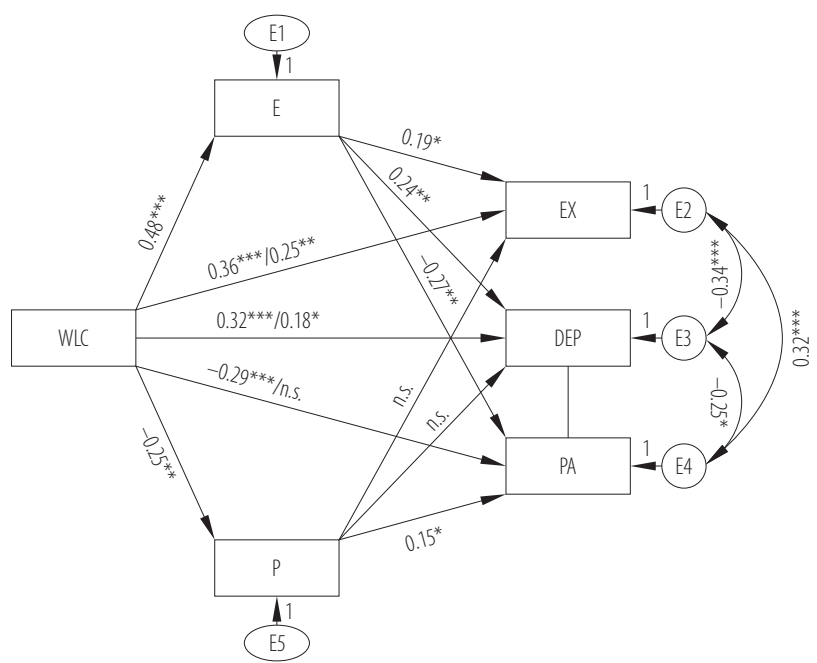

n.s. - non-significant; $\mathrm{E}_{1-5}$ - error markers.

Other abbreviations as in Table 1 .

* $\mathrm{p}<0.05 ; *$ * $<0.01 ; * *$ p $<0.001$.

Fig. 1. Emotion and problem-focused styles as mediators in the relationship between work locus of control and burnout

$\mathrm{p}<0.05)$ and depersonalization $(\mathrm{r}=-0.16, \mathrm{p}<0.05)$, and showed positive correlation with personal accomplishment $(\mathrm{r}=0.20, \mathrm{p}<0.05)$. No significant correlations were found between avoidance-oriented coping style and components of burnout. The external work locus of control correlated positively with

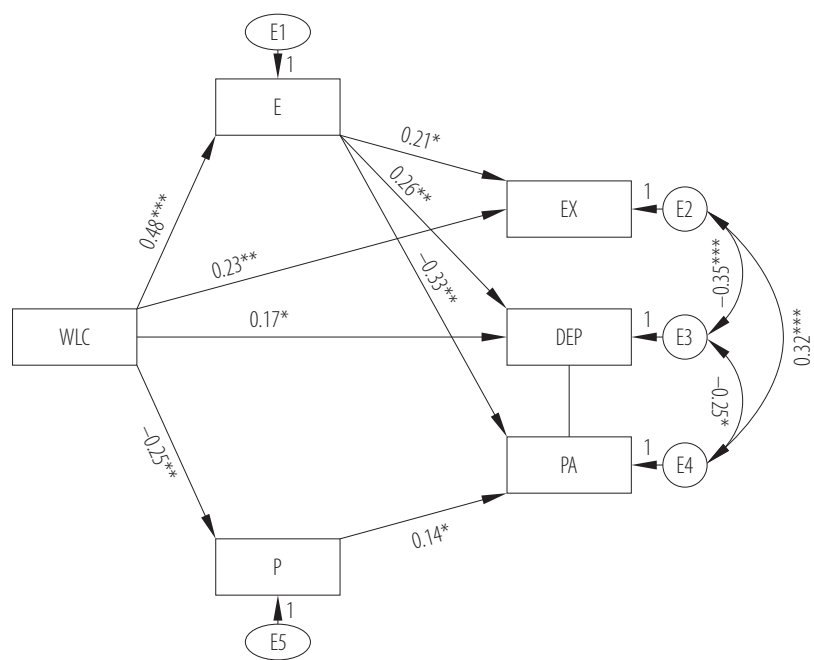

Abbreviations as in Table 1 and Figure 1.

* $\mathrm{p}<0.05 ;{ }^{* *} \mathrm{p}<0.01 ;{ }^{* * *} \mathrm{p}<0.001$.

Fig. 2. Adjusted model: Emotion and problem-focused styles as mediators in the relationship between work locus of control and burnout

emotional exhaustion $(\mathrm{r}=0.36, \mathrm{p}<0.001)$ and depersonalization $(r=0.32, p<0.001)$, and was inversely correlated with personal accomplishments $(r=-0.29, p<0.001)$. In total mediation model, shown in Figure 1, the relationships between work locus of control and burnout subscales were controlled after the introduction of 
the mediators - styles of coping with stress. Correlations (in these cases, equal to the standardized regression coefficients) between work locus of control and the components of burnout were also placed on the arrows corresponding to the direct relationship between these variables. The regression coefficients obtained after the introduction of the mediators are presented next to them (Figure 1). The model does not include an avoidance style since it was not significantly associated with any of the burnout components.

The 1st model fitted well with the data $\left(\mathrm{Chi}^{2}=0.301\right.$, $\mathrm{df}=1, \mathrm{p}=0.583, \mathrm{CFI}=1.000$, RMSEA $=0.001$ ). Emotion-focused coping style was identified as a mediator of the relationship between work locus of control, emotional exhaustion and depersonalization (Figure 1). Standardized regression coefficients between work locus of control and coping styles were equal to the correlation coefficient (work locus of control - emotion-focused style: $\beta=0.48$, $\mathrm{p}<0.001$; work locus of control - problem-focused coping style: $\beta=-0.25, p<0.05)$. Primary relationships between work locus of control and burnout remained significant at 0.05 in the total model (work locus of control - emotional exhaustion: $\beta=0.25, p<0.01$; work locus of control - depersonalization: $\beta=0.18, p<0.05)$. Also the relationships between emotional style, emotional exhaustion $(\beta=0.19$, $\mathrm{p}<0.05)$ and depersonalization $(\beta=0.24, \mathrm{p}<0.01)$ proved to be significant (Figure 1).

Mediation effect was found in the case of the relationships: work locus of control - stress coping styles - personal accomplishment. The power of primary relationship between work locus of control and job satisfaction decreased to a statistically insignificant value. Both emotion- and problem-focused styles turned out to be mediators in this case. Relationships between these styles and personal accomplishments remained significant (emotion-focused style: $\beta=-0.27, p<0.01$; problem-focused style: $\beta=0.15, \mathrm{p}<0.05$ ) (Figure 1).

Indirect effects for the tested relationships were as follows: work locus of control - stress coping styles-emotional exhaustion (0.114, 95\% CI: 0.002-0.232), work locus of control - stress coping styles - depersonalization (0.141, 95\% CI: 0.049-0.261), work locus of control - stress coping styles - personal accomplishment $(-0.166,95 \%$ CI: -0.274 to -0.082$)$. The variables explained approximately $17 \%$ of variance in emotional exhaustion, and $16 \%$ of variance in depersonalization and professional satisfaction. Subsequently, the model was adjusted by elimination of the statistically insignificant relations (Figure 2).

Now, the 2nd model (adjusted model) will be examined (Figure 2). The model fitted well with the data $\left(\mathrm{Chi}^{2}=0.476, \mathrm{df}=4, \mathrm{p}=0.313, \mathrm{CFI}=0.995, \mathrm{RM}-\right.$ SEA $=0.035)$. The relationship between the mediators of other variables were very similar to the relationships shown in the previously presented model. The total indirect effects of the tested relationships were as follows: work locus of control - stress coping styles emotional exhaustion (0.102, 95\% CI: 0.012-0.197), work locus of control - stress coping styles - depersonalization (0.123, 95\% CI: 0.037-0243), work locus of control - stress coping styles - personal accomplishment $(-0.193,95 \%$ CI: -0.29 to -0.082$)$. The variables explained about $15 \%$ of the variance in emotional exhaustion, and $14 \%$ of variance in depersonalization and personal accomplishment.

\section{DISCUSSION}

The main objective of this study was to determine whether different coping styles mediate the relationship between work locus of control and burnout symptoms in physiotherapists. We hypothesized that the relationship between work locus of control and burnout symptoms would be mediated by associations with the problem-focused, emotion-focused and avoidant coping styles. These assumptions were partially confirmed as the relationship between external work locus of control and burnout was shown to be mediated by emotion- and problem-focused coping. 
We found positive relationships between external work locus of control and the emotion-focused style, and between the emotion-focused style and burnout.

Furthermore, we demonstrated inverse relationships between external work locus of control and the problemfocused style of coping with stress, and between the problem-focused style and burnout. The indirect effects for these mediators were statistically significant. The relationships between locus of control, emotional exhaustion and depersonalization remained statistically significant after introducing a mediator, which may point to partial mediation. However, modern researchers avoid such terminology and interpretation and pay more attention to the aforementioned test of indirect effects together with a prior factual justification for mediation $[74,76,78]$.

The results of our study add several important theoretical contributions to the existing knowledge about burnout in medical professions. First, our findings support the results of previous empirical studies that showed an important relationship between work locus of control, coping strategies and burnout symptoms. According to Folkman and Lazarus [79], there is a general tendency to use the problemfocused strategy if situations are perceived as changeable, and emotion-focused coping in situations not amenable to change. Our study confirmed these relationships.

Moreover, our study provided some new theoretical insights. Although most previous studies demonstrated a positive relationship between external work locus of control and burnout, some authors found different directions of this connection. For example, Rijk et al. [63] showed that high level of job control increases emotional exhaustion of people using the passive coping style, while individuals using the active coping style feel less emotionally exhausted. Consequently, the employed strategy can be mainspring of burnout development. Our findings provide support for this assumption, indicating that part of the work locus of control - burnout symptoms association is mediated by coping practices. Specifically, emotion-oriented coping promotes negative influence of external work locus of control on burnout. Therefore, one may assume that an improvement of emotion regulation might contribute significantly to the reduction of burnout symptoms.

Furthermore, our findings add to existing evidence on the mediating role of coping strategies. A similar previous study conducted by Elfstrom and Kreuter [66] analyzed the associations between emotional well-being, locus of control and coping strategies in a sample of 132 persons with spinal cord lesions. The study confirmed that the link between locus of control and emotional well-being is mediated by coping strategies. Persons indicating internal control reported more coping strategies related to improved well-being, while individuals with external control reported more coping strategies related to poorer well-being. Having in mind the differences between both studies at the theoretical level, we can conclude that our results confirmed the findings of Elfstrom and Kreuter to a large extent.

Surprisingly, our study did not confirm the mediating role of the avoidance-oriented style of coping with stress. This is inconsistent with the results of previous studies which showed that avoidance coping strategies are associated with increased burnout $[4,58,80]$ and can be considered a mediator of the latter $[81,82]$. This discrepancy may result from the specific nature of avoidance coping strategies. Although avoidant behaviors may be helpful in dealing with problems and their negative consequences, they turn out to be detrimental to mental health in the long perspective. Therefore, a lot depends on the experience of the person using the avoidance strategy. In the case of this particular strategy, the most reliable data originate from the longitudinal studies, which showed that avoidance is associated with more chronic and more acute life stressors in most cases [83]. The only relationship that emerged in the context of avoidance strategies was related to external work locus of control. The physiotherapists who perceived 
the situation as uncontrollable were more likely to manifest avoidant coping behaviors. This finding is consistent with the results of previous studies $[84,85]$.

Our study has several practical implications. Physiotherapists who are burned out may be less productive and less engaged in their work, which affects their efficiency and patient satisfaction. Patients working with a burned out physiotherapist are at risk of not receiving optimal care, which significantly increases the cost of treatment at both individual and organizational level. Therefore, research aimed at the identification of factors affecting the burnout process in this occupational group is particularly important.

Our findings point to 2 ways of reducing the risk of burnout. First, managers of medical facilities should take steps to create working conditions, which will contribute to shaping the internal sense of control at work. This means, inter alia, engaging employees in the process of planning work, and creating transparent work rules. Managers should also consider the rotation of staff on the wards, which allows physical therapists to work with different groups of patients and prevent the monotony and routine. Obviously, this idea should be preceded by a conversation with the employees and refers to those institutions in which it is feasible and to physiotherapists who are not specialists. Moreover, it is extremely important to allow the physiotherapists to participate in the decision-making regarding the treatment of patients; this significantly increases their level of autonomy, and creates favorable conditions for the development of internal locus of control.

The 2nd way of reducing burnout is by improving adoption of problem-focused coping in the face of work demands. It could be achieved by organizing seminars, workshops, social skill trainings to promote problem-focused strategies, even if the situation seems to be out of control. This type of training also contributes to building a greater sense of control, since these variables are dependent on each other [86]. The use of problem-focused strategy fosters a sense of internal control, and this in turn increases the likelihood of using problem-focused strategies. Several limitations of this study should be mentioned. First, the data were obtained through self-report, which is subjected to a bias and distortion. Respondents could answer questions under the influence of other, non-audited situational factors. Second, our study was cross-sectional, which precludes any conclusions about causal directions. Hence, we cannot exclude that it was burnout which affected the physiotherapists' perception of situation controllability and choice of strategies. Therefore, longitudinal studies would be necessary to further explore this matter.

Third, the interpretation of the current findings may suffer from limited generalizability. We examined a group of physiotherapists working in the Polish healthcare system, which is different from the systems in other countries, particularly in terms of the role of the physiotherapist in the process of comprehensive rehabilitation. However, we analyzed the relationships between the variables that have been confirmed in a large number of other studies. We did not diagnose the situation, but sought the mechanisms behind already proven relationships. Obviously, future research should be undertaken in culturally-diverse countries, where autonomy and active coping are perceived differently than in countries with an individualistic culture $[87,88]$. The examined relationships may be quite different in ethnically- and culturally-diverse groups.

Fourth, there is lack of validation studies on Polish version of Work Locus of Control Scale, therefore, the results should be interpreted with caution. Finally, we cannot exclude the impact of other sociodemographic, situational and personal factors on the results. A number of previous studies documented the relationships between burnout symptoms and other variables. The search for other mediators of the relationship between work locus of control and burnout should contribute to an even greater clarification of this association. 


\section{CONCLUSIONS}

The present study provides new insight in the relationship between work locus of control and burnout symptoms in physiotherapists. Specifically, we explained this relationship by demonstrating that external work locus of control was positively related to burnout through the emotionfocused style of coping with stress and inversely related to burnout through the problem-focused style of coping with stress. Consequently, physiotherapists perceiving the situation as difficult to control, feel more burned out when they use more emotion-focused and less problem-focused strategies. Hence, the problem-focused and emotionfocused coping style can be considered as a mediator of a relationship between work locus of control and burnout syndrome. This points to the importance of including problem-focused coping training and increasing the perception of the situation controllability in the programs aimed at prevention of burnout among physiotherapists.

\section{REFERENCES}

1. Maslach C. Burnout: The cost of caring. New York: PrenticeHall; 1982.

2. Leiter MP. Perception of risk: An organizational model of occupational risk, burnout, and physical symptoms. Anxiety Stress Coping. 2005;18(2):131-44, http://dx.doi. org/10.1080/10615800500082473.

3. Michinov N. Social comparison, perceived control, and occupational burnout. Appl Psychol. 2005;54(1):99-118, http:// dx.doi.org/10.1111/j.1464-0597.2005.00198.x.

4. Leiter MP. Coping patterns as predictors of burnout: The function of control and escapist coping patterns. J Organ Behav. 1991;12(2):123-44, http://dx.doi.org/10.1002/ job.4030120205.

5. Maslach C, Jackson SE, Leiter MP. The Maslach Burnout Inventory. 3rd ed. Palo Alto (CA): Consulting Psychologists Press; 1996.

6. Lee RT, Ashforth BE. A meta-analytic examination of the correlates of the three dimensions of job burnout. J Appl
Psychol. 1996;81:123-33, http://dx.doi.org/10.1037/0021-90 10.81.2.123.

7. Halbesleben JR, Buckley MR. Burnout in organizational life. J Manage. 2004;30(6):859-79, http://dx.doi. org/10.1016/j.jm.2004.06.004.

8. Altun I. Burnout and nurses' personal and professional values. Nurs Ethics. 2002;9(3):269-78, http://dx.doi.org/10. 1191/0969733002ne509oa.

9. Heyns PM, Venter JH, Esterhuyse KG, Bam RH, Odendaal DC. Nurses caring for patients with Alzheimer's disease: Their strengths and risk of burnout. S Afr J Psychol. 2003; 33(2):80-5, http://dx.doi.org/10.1177/008124630303300202.

10. Lee RT, Seo B, Hladkyj S, Lovell BL, Schwartzmann L. Correlates of physician burnout across regions and specialties: A meta-analysis. Hum Resour Health. 2013;11(1): 48, http://dx.doi.org/10.1186/1478-4491-11-48.

11. Peisah C, Latif E, Wilhelm K, Williams B. Secrets to psychological success: Why older doctors might have lower psychological distress and burnout than younger doctors. Aging Ment Health. 2009;13(2):300-7, http://dx.doi. org/10.1080/13607860802459831.

12. Cronin-Stubbs D, Brophy EB. Burnout: Can social support save the psychiatric nurse? J Psychosoc Nurs. 1985;23:8-13.

13. Lewiston NJ, Conley J, Blessing-Moore J. Measurement of hypothetical burnout in cystic fibrosis caregivers. Acta Paediatr. 1981;70(6):935-9, http://dx.doi. org/10.1111/j.1651-2227.1981.tb06254.x.

14. Li Calzi S, Farinelli M, Alianti L, Manigrasso V, Taroni AM. Physical rehabilitation and burnout: Different aspect of the syndrome and comparison between healthcare professionals involved. Eura Medicophys. 2006;42:27-36.

15. Ogiwara S, Hayashi H. Burnout amongst physiotherapists in Ishikawa Prefecture. J Phys Ther Sci. 2002;14(1):7-13, http://dx.doi.org/10.1589/jpts.14.7.

16. Donohoe E, Nawawi A, Wilker L, Schindler T, Jette UDE. Factors associated with burnout of physiotherapists in Massachusetts rehabilitation hospitals. Phys Ther. 1993;73(11):750-61. 
17. Pavlakis A, Raftopoulos V, Theodorou M. Burnout syndrome in Cypriot physiotherapists: A national survey. BMC Health Serv Res. 2010;10:63, http://dx.doi.org/10.1186/1472-6963-10-63.

18. Fernet C, Guay F, Senecal C. Adjusting to job demands: The role of work self-determination and job control in predicting burnout. J Vocat Behav. 2004;65:39-56, http://dx.doi. org/10.1016/S0001-8791(03)00098-8.

19. Maslach C, Schaufeli WB, Leiter MP. Job burnout. Ann Rev Psychol. 2001;52(1):397-422, http://dx.doi.org/10.1146/ annurev.psych.52.1.397.

20. Ilies R, Johnson MD, Judge TA, Keeney J. A within-individual study of interpersonal conflict as a work stressor: Dispositional and situational moderators. J Organ Behav. 2011;32:44-64, http://dx.doi.org/10.1002/job.677.

21. Bond FW, Bunce D. Job control mediates change in a work reorganization intervention for stress reduction. J Occup Health Psych. 2001;6:290-302, http://dx.doi. org/10.1037/1076-8998.6.4.290.

22. Gan Y, Shang J, Zhang Y. Coping flexibility and locus of control as predictors of burnout among Chinese college students. Soc Behav Pers. 2007;35(8):1087-98, http://dx.doi. org/10.2224/sbp.2007.35.8.1087.

23. Rotter JB. Generalized expectancies for internal versus external control of reinforcement. Psychol Monogr. 1966; 80(1):1, http://dx.doi.org/10.1037/h0092976.

24. Rotter JB. Some problems and misconceptions related to the construct of internal versus external control of reinforcement. J Consult Clin Psychol. 1975;43:56-67, http://dx.doi. org/10.1037/h0076301.

25. Muhonen T, Torkelson E. Work locus of control and its relationship to health and job satisfaction from a gender perspective. Stress Health. 2004;20(1):21-8, http://dx.doi. org/10.1002/smi.994.

26. Spector PE. Development of the Work Locus of Control Scale. J Occup Psychol. 1988;61:335-40, http://dx.doi. org/10.1111/j.2044-8325.1988.tb00470.x.

27. Spector PE, Cooper CL, Sanchez JI, O’Driscoll M, Sparks K, Bernin P, et al. Do national levels of individualism and internal locus of control relate to wellbeing: An ecological level international study. J Organ Behav. 2001;22:815-32, http://dx.doi.org/10.1002/job.118.

28. Tong J, Wang L. Validation of locus of control scale in Chinese organizations. Pers Individ Differ. 2006;41(5):941-50, http://dx.doi.org/10.1016/j.paid.2006.03.018.

29. Lu L, Kao SF, Cooper CL, Spector PE. Managerial stress, locus of control, and job strain in Taiwan and UK: A comparative study. Int J Stress Manage. 2000;7:209-26, http:// dx.doi.org/10.1023/A:1009518315691.

30. McKnight JD, Glass DC. Perceptions of control, burnout, and depressive symptomatology: A replication and extension. J Consult Clin Psychol. 1995;63(3):490-4, http://dx.doi. org/10.1037/0022-006X.63.3.490.

31. Tong J, Wang L. Work locus of control and its relationship to stress perception, related affections, attitudes and behaviours from a domain-specific perspective. Stress Health. 2012;28(3):202-10, http://dx.doi.org/10.1002/ smi.1423.

32. Furnham A, Drakeley RJ. Work locus of control and perceived organizational climate. Eur Work Organ Psychol. 1993;3:1-9, http://dx.doi.org/10.1080/09602009308408572.

33. Lievens F, de Corte W, Schollaert E. A closer look at the frame-of-reference effect in personality scale scores and validity. J Appl Psychol. 2008;93:268-79, http://dx.doi. org/10.1037/0021-9010.93.2.268.

34. Tillman JT, Smith F, Tillman W. Work locus of control and the multidimensionality of job satisfaction. J Organ Cult Commun Confl. 2010;14(2):107-25.

35. Wang Q, Bowling NA, Eschleman KJ. A meta-analytic examination of work and general locus of control. J Appl Psychol. 2010;95(4):761-8, http://dx.doi.org/10.1037/a0017707.

36. Mikrut G, Bacik B, Czuba M. Physiotherapist as an occupation - Legal status in Poland. Physiotherapy. 2011;19(2): 69-78, http://dx.doi.org/10.2478/v10109-011-0002-x.

37. Enberg B, Nordin C, Öhman A. Work experiences of novice occupational therapists and physiotherapists in public sector employment - Analyses using two occupational 
stress models. Adv Physiother. 2010;12:42-9, http://dx.doi. org/10.3109/14038190903033161.

38. Kowalska J. [Professional burnout in Polish physiotherapists]. Postepy Rehabil. 2011;3:43-52, http://dx.doi. org/10.2478/rehab-2013-0014. Polish.

39. Włoszczak-Szubzda A, Jarosz MJ. Professional communication competences of physiotherapists - Practice and educational perspectives. Ann Agric Environ Med. 2013;20(1):189-94.

40. Hätinen M, Kinnunen U, Pekkonen M, Kalimo R. Comparing two burnout interventions: Perceived job control mediates decreases in burnout. Int J Stress Manage. 2007;14(3): 227-48, http://dx.doi.org/10.1037/1072-5245.14.3.227.

41. Schmitz N, Neumann W, Oppermann R. Stress, burnout and locus of control in German nurses. Int $\mathrm{J}$ Nurs Stud. 2000;37:95-9, http://dx.doi.org/10.1016/S0020-7489 (99)00069-3.

42. Koeske GF, Kirk SA. Direct and buffering effects of internal locus of control among mental health professionals. J Soc Serv Res. 1995;20(3-4):1-28, http://dx.doi.org/10. 1300/J079v20n03_01.

43. Lourel M, Abdellaoui S, Chevaleyre S, Paltrier M, Gana K. Relationships between psychological job demands, job control and burnout among firefighters. North Am J Psychol. 2008;10(3):489-96.

44. Ng TWH, Sorensen KL, Eby L. Locus of control at work: A meta-analysis. J Organ Behav. 2006;27:1057-87, http:// dx.doi.org/10.1002/job.416.

45. Hipps ES, Malpin G. The relationship of locus of control, stress related to performance-based accreditation, and job stress to burnout in public school teachers and principals. Paper presented at the Annual Meeting of the American Educational Research Association; 1991 Apr 3-7; Chicago (IL), USA. ERIC Document Reproduction Service No. Ed. 333557.

46. Hochwalder J. The psychosocial work environment and burnout among Swedish registered and assistant nurses: The main, mediating, and moderating role of empower- ment. Nurs Health Sci. 2007;9:205-11, http://dx.doi.org/10.11 11/j.1442-2018.2007.00323.x.

47. Schaubroeck J, Merritt DE. Divergent effects of job control on coping with work stressors: The key role of selfefficacy. Acad Manage J. 1997;40(3):738-54, http://dx.doi. org/10.2307/257061.

48. Lazarus RS, Folkman S. Stress, appraisal, and coping. New York: Springer; 1984.

49. Endler NS, Parker JDA. Multidimensional assessment of coping: A critical evaluation. J Pers Soc Psychol. 1990; 58:844-54, http://dx.doi.org/10.1037/0022-3514.58.5.844.

50. Endler NS, Parker JDA. Assessment of multidimensional coping: Task, emotion and avoidance strategies. Psychol Assess. 1994;1:50-60, http://dx.doi.org/10.1037/1040-3590. 6.1.50.

51. Parker JDA, Endler NS. Coping and defense: A historical overview. In: Zeidner M, Endler NS, editors. Handbook of coping: Theory, research, applications. New York: Wiley; 1996. p. 3-23.

52. Elliott TR, Shewchuk R, Hagglund K, Rybarczyk B, Harkins S. Occupational burnout, tolerance for stress, and coping among nurses in rehabilitation units. Rehabil Psychol. 1996; 41(4):267-84, http://dx.doi.org/10.1037/0090-5550.41.4.267.

53. Garrosa E, Rainho C, Moreno-Jimenez B, Monteiro MJ. The relationship between job stressors, hardy personality, coping resources and burnout in a sample of nurses: A correlational study at two time points. Int J Nurs Stud. 2010; 47:205-15, http://dx.doi.org/10.1016/j.ijnurstu.2009.05.014.

54. Koeske GF, Kirk SA, Koeske RD. Coping with job stress: Which strategies work best? J Occup Organ Psych. 1993;66(4): 319-35, http://dx.doi.org/10.1111/j.2044-8325.1993.tb00542.x.

55. Carmona C, Buunk AP, Peiro JM, Rodriguez I, Bravo MJ. Do social comparison and coping styles play a role in the development of burnout? Cross-sectional and longitudinal findings J Occup Organ Psych. 2006;79(1):85-99, http:/ dx.doi.org/10.1348/096317905X40808.

56. Wilkerson K, Bellini J. Intrapersonal and organizational factors associated with burnout among school counselors. 
J Couns Dev. 2006;84(4):440-50, http://dx.doi.org/10.1002/ j.1556-6678.2006.tb00428.x.

57. Anderson DG. Coping strategies and burnout among veteran child protection workers. Child Abuse Negl. 2000;24(6): 839-48, http://dx.doi.org/10.1016/S0145-2134(00)00143-5.

58. Ceslowitz SB. Burnout and coping strategies among hospital staff nurses. J Adv Nurs. 1989;14:553-5, http://dx.doi. org/10.1111/j.1365-2648.1989.tb01590.x.

59. Thornton PI. The relation of coping, appraisal, and burnout in mental health workers. J Psychol. 1992;126(3): 261-71, http://dx.doi.org/10.1080/00223980.1992.10543360.

60. Michielsen HJ, Croon MA, Willemsen TM, de Vries J, van Heck GL. Which constructs can predict emotional exhaustion in a working population? A study into its determinants. Stress Health. 2007;23(2):121-30, http://dx.doi. org/10.1002/smi.1129.

61. Triplett R, Mullings J, Scarborough KE. Work-related stress and coping among correctional officers: Implications from organizational literature. J Crim Justice. 1996;24:291-308, http://dx.doi.org/10.1016/0047-2352(96)00018-9.

62. Hurrell JJ. Police work, occupational stress and individual coping. J Organ Behav. 1995;16:27-8, http://dx.doi. org/10.1002/job.4030160105.

63. Rijk AE, Blanc PML, Schaufeli WB, Jonge J. Active coping and need for control as moderators of the job demand - Control model: Effects on burnout. J Occup Organ Psychol. 1998;71(1):1-18, http://dx.doi.org/10.1111/ j.2044-8325.1998.tb00658.x.

64. Herman-Stabl MA, Stemmler M, Petersen AC. Approach and avoidant coping: Implications for adolescent mental health. J Youth Adolesc. 1995;24(6):649-65, http://dx.doi. org/10.1007/BF01536949.

65. Arslan C, Dilmac B, Hamarta E. Coping with stress and trait anxiety in terms of locus of control: A study with Turkish university students. Soc Behav Pers. 2009;37(6):791-800, http://dx.doi.org/10.2224/sbp.2009.37.6.791.

66. Elfström ML, Kreuter M. Relationships between locus of control, coping strategies and emotional well-being in persons with spinal cord lesion. J Clin Psychol Med S. 2006; 13(1):89-100, http://dx.doi.org/10.1007/s10880-005-9001-8.

67. Hoffman MA, Levy-Shiff R. Coping and locus of control. Cross-generational transmission between mothers and adolescents. J Early Adolesc. 1994;14(3):391-405, http://dx.doi. org/10.1177/0272431694014003005.

68. Liu X, Kurita H, Uchiyama M, Okawa M, Liu L, Ma D. Life events, locus of control, and behavior problems among Chinese adolescents. J Clin Psychol. 2000;56:1565-77, http://dx.doi.org/10.1002/1097-4679(200012)56:12<1565 ::AID-7>3.0.CO;2-U.

69. Pasikowski T. [Polish adaption of Maslach Burnout Inventory Questionnaire]. In: Sęk H, editor. [Burnout. Causes and prevention]. Warszawa: Wydawnictwo Naukowe PWN; 2009. p. 135-49. Polish.

70. Schaufeli WB, Enzmann D. The burnout companion to study and practice: A critical analysis. London: CRC Press; 1998.

71. Breeding RR. Empowerment as a function of contextual self-understanding the effect of work interest profiling on career decision self-efficacy and work locus of control. Rehabil Couns Bull. 2008;51(2):96-106, http://dx.doi. org $/ 10.1177 / 0034355207311346$.

72. Strelau J, Jaworowska A, Wrześniewski K, Szczepaniak P. [Questionnaire of Coping with Stressful Situations - CISS]. Warszawa: Pracownia Testów Psychologicznych; 2007. Polish.

73. Endler NS, Parker JDA. The Coping Inventory for Stressful Situations (CISS): Manual. 2nd ed. Toronto: Multi-Health Systems; 1999.

74. Hayes AF. Beyond Baron and Kenny: Statistical mediation analysis in the new millennium. Commun Monogr. 2009; 76(4):408-20, http://dx.doi.org/10.1080/03637750903310360.

75. Hayes AF. Introduction to mediation, moderation, and conditional process analysis: A regression-based approach. New York: Guilford Press; 2013.

76. Zhao X, Lynch JG, Chen Q. Reconsidering Baron and Kenny: Myths and truths about mediation analysis. J Consum Res. 2010;37(2):197-206, http://dx.doi.org/10.1086/651257. 
77. Hu LT, Bentler PM. Cutoff criteria for fit indexes in covariance structure analysis: Conventional criteria versus new alternatives. Struct Equ Modeling. 1999;6(1):1-55, http:// dx.doi.org/10.1080/10705519909540118.

78. Rucker DD, Preacher KJ, Tormala ZL, Petty RE. Mediation analysis in social psychology: Current practices and new recommendations. Soc Pers Psychol Compass. 2011;5(6):359-71, http://dx.doi.org/10.1111/j.1751-90 04.2011.00355.x.

79. Folkman S, Lazarus RS. An analysis of coping in a middleaged community sample. J Health Soc Behav. 1980;21: 219-39, http://dx.doi.org/10.2307/2136617.

80. Van der Colff JJ, Rothmann S. Occupational stress, sense of coherence, coping, burnout and work engagement of registered nurses in South Africa. S Afr J Ind Psychol. 2009;35(1), http://dx.doi.org/10.4102/sajip.v35i1.423.

81. Chen MJ, Cunradi C. Job stress, burnout and substance use among urban transit operators: The potential mediating role of coping behaviour. Work Stress. 2008;22(4):327-40, http://dx.doi.org/10.1080/02678370802573992.

82. Hill AP, Hall HK, Appleton PR. Perfectionism and athlete burnout in junior elite athletes: The mediating role of coping tendencies. Anxiety Stress Coping. 2010;23(4):415-30, http://dx.doi.org/10.1080/10615800903330966.
83. Holahan CJ, Moos RH, Holahan CK, Brennan PL, Schutte KK. Stress generation, avoidance coping, and depressive symptoms: A 10-year model. J Consult Clin Psychol. 2005; 73(4):658-66, http://dx.doi.org/10.1037/0022-006X.73.4.658.

84. Gomez R. Locus of control and type A behavior pattern as predictors of coping styles among adolescents. Pers Individ Dif. 1997;23(3):391-8, http://dx.doi.org/10.1016/S01918869(97)00065-2.

85. Scott SL, Carper TM, Middleton M, White R, Renk K, Grills-Taquechel A. Relationships among locus of control, coping behaviors, and levels of worry following exposure to hurricanes. J Loss Trauma. 2010;15(2):123-37, http://dx.doi. org/10.1080/15325020902925985.

86. Spence SH. Cognitive therapy with children and adolescents: From theory to practice. J Child Psychol Psychiatry. 1994;35(7):1191-228, http://dx.doi.org/10.1111/ j.1469-7610.1994.tb01230.x.

87. Diener E, Diener M. Cross-cultural correlates of life satisfaction and self-esteem. J Pers Soc Psychol. 1995;68: 653-63, http://dx.doi.org/10.1037/0022-3514.68.4.653.

88. Diener E, Oishi S, Lucas R. Personality, culture, and subjective well-being: Emotional and cognitive evaluations of life. Ann Rev Psychol. 2003;54:403-25, http://dx.doi.org/10.1146/ annurev.psych.54.101601.145056.

This work is available in Open Access model and licensed under a Creative Commons Attribution-NonCommercial 3.0 Poland License - http://creativecommons.org/ licenses/by-nc/3.0/pl/deed.en. 